\title{
Surface Characterization of Titanium Based Dental Implants
}

\author{
Guilherme A. A. Castilho, Maximiliano D. Martins, and Waldemar A. A. Macedo \\ Laboratório de Física Aplicada, Centro de Desenvolvimento da Tecnologia Nuclear 31270-901, Belo Horizonte, MG, Brazil
}

Received on 8 December, 2005

\begin{abstract}
The study of dental implant surfaces is relevant in order to better understand the interaction of the titanium surface and the surrounding tissues. Clinical success is achieved not only because of implant material but also because of other properties as implant design, surface treatment and quality. In this work, we report a detailed surface investigation of three major Brazilian made implants and compared them to a world-known implant. The surface composition and morphology were investigated by using X-ray photoelectron spectroscopy and scanning electron microscopy. Results of a biological test implemented in order to verify the bioactivity of the implant surface are also presented.
\end{abstract}

Keywords: Titanium implants; Dental implants; Surface morphology

\section{INTRODUCTION}

Since Branemark and coworkers introduced the use of screw shaped commercially pure (cp-Ti) titanium implants for oral rehabilitation, an increasing number of dental and orthopedic implants are placed in patients every year. Titanium and its alloys are among the most commonly used implant materials, particularly for dental, orthopedic and osteosynthesis applications $[1,2]$. These materials are known to have a combination of good properties making them particularly relevant and suited for biomedical applications. Titanium shows a favorable combination of intrinsic properties for the fabrication of dental implants such as low specific weight, high strength to weight ratio, low modulus of elasticity, very high corrosion resistance and excellent general biocompatibility [3]. The passive oxide layer that forms on the titanium implant surfaces protects the underlying metal from further oxidation and allows the osseointegration.

Clinical success is achieved not only because of implant material but also because of other properties as implant design, surface treatment and quality, besides other implications as surgery technique, host bone quality and load bearing [4]. Among all of titanium properties one of the most important is the surface quality [5]. Titanium oxide compounds, present on the surface of commercially pure titanium implants, are responsible for the favorable biological interaction that occur on the bone-fixation interface. This oxide layer provides titanium biocompatible features [6]. Chemical composition of the implant surface can differ markedly from bulk composition due to manufacturing finishing such as machining, thermal treatment, blasting, etching, coatings and even sterilization procedures. Surface contamination introduced by these procedures, as for example, traces of metals, ions, lubricants, and detergents may alter for better or worse the surface biocompatibility even when present in small quantities. Based on these considerations, a careful control of implant surface composition becomes a relevant procedure to produce high quality devices [7-9].

Studies on surface characteristics using photoelectron spectroscopy and electron microscopy among other surface techniques have been seeing in literature [10-13]. It has also been observed that there is a lack of surface properties investiga- tion of Brazilian made dental implants. In the present work, we report a detailed study on the chemical and morphological properties of three different Brazilian made dental implants available on market (Neodent, SIN and Conexão). A world wide known implant system from Nobel Biocare [14,15] were also characterized and used as standard, and the results were compared to that obtained for the Brazilian implants. The surface composition and morphology were investigated using Xray photoelectron spectroscopy (XPS) and scanning electron microscopy (SEM). A biological test was implemented in order to verify bioactivity of the samples. The dental implants were immersed in simulated body fluid (SBF) during 21 days. After SBF immersion test the implants surface were analysed by XPS. The formation of an apatite-like layer on the implant surface was investigated.

\section{EXPERIMENTAL PROCEDURE}

For implants of four different manufacturers, two types of surface finishing have been analysed in terms of surface morphology and composition, machined implants: Branemark MKIII (Nobel Biocare, Gotenburg, Sweden), Master (Conexão, São Paulo, Brazil), Titamax Liso (Neodent, $\mathrm{Cu}-$ ritiba, Brazil) and Revolution (SIN, São Paulo, Brazil) and porous implants: Branemark MKIII TiUnite (Nobel Biocare, Gotenburg, Sweden), Master Porous (Conexão, São Paulo, Brazil), Titamax Porous (Neodent, Curitiba, Brazil) and Revolution Superfície Ativada (SIN, São Paulo, Brazil). They were kept in original sterile packaging until the attachment to a sample-holder in order to permit handling inside the vacuum chamber. This procedure was carefully controlled to prevent contamination during manipulation and never exceeded five minutes before vacuum insertion. XPS photoemission spectra of the dental implants were collected using a CLAM2 Microtech electron analyser and $\mathrm{Al} \mathrm{K} \alpha$ radiation $(1486.6 \mathrm{eV})$. Wide scan photoemission spectra were recorded with pass energy of $50 \mathrm{eV}$ and normal emission. The elemental surface composition was calculated by normalizing the relative spectral peak areas $(A)$ using relative sensitivity factors $S$ [16], as illustrated in the equation 


$$
C_{x}=\frac{A_{x}}{S_{x}} / \sum_{i} \frac{A_{i}}{S_{i}} .
$$

Surface bioactivity was assessed through immersion of each sample into a polypropylene flask containing $30 \mathrm{ml}$ of SBF for the period of 21 days. This test is commonly used to check in vitro deposition of a superficial hydroxyapatite layer when a biomaterial is in contact with constituents of corporal fluids [16]. SBF solution was prepared by dissolving reagent-grade $\mathrm{NaCl}, \mathrm{NaHCO}_{3}, \mathrm{KCl}, \mathrm{Na}_{2} \mathrm{HPO}_{4} \cdot 7 \mathrm{H}_{2} \mathrm{O}$, $\mathrm{MgCl}_{2} \cdot 6 \mathrm{H}_{2} \mathrm{O}, \mathrm{CaCl}_{2}$ and $\mathrm{NaSo} 4$ on distilled water containing buffering agent, $\mathrm{HCl}$ and $\left(\mathrm{CH}_{2} \mathrm{OH}\right)_{3} \mathrm{CNH}_{2}$ at $\mathrm{pH}$ 7.25. The immersed implants were kept at $37^{\circ} \mathrm{C}$ for 21 days, after that they were rinsed in distilled water and dried. XPS wide scans were also performed after SBF immersion. Scanning electron microscopy investigations of the implants were performed just after removing them from the sterile packaging using a JEOL JSM-5310 microscope. The beam acceleration voltage was 25 $\mathrm{kV}$ and themagnification ranged from 35 to 3500 .

\section{RESULTS}

Surface elemental composition (\% atomic concentration), as measured by XPS analysis, is presented in Table I and II. Different implants were labeled according to manufacturer: (1) Neodent, (2) SIN, (3) Conexão and (4) Nobel. Table I presents the surface elemental composition of machined (M) and porous $(\mathrm{P})$ surface implants before (B) immersion in SBF. Table II shows the surface elemental composition for machined (M) and porous (P) implants after (A) 21 days of immersion in SBF. Constituent elements of SBF solution such as $\mathrm{Ca}, \mathrm{P}, \mathrm{Na}$ and $\mathrm{Cl}$ were observed with concentration varying from trace concentration $(<1 \%)$ to $\sim 4 \%$.

The XPS analysis and surface elemental composition for machined implants from Neodent, SIN and Conexão presented similar amounts of titanium dioxide and carbon compounds. Traces of nitrogen appeared for all brands. Traces of silicon were observed in Conexão implant. On our studies, Nobel Biocare machined implant did not presented representative amount of any other element but titanium (oxide), oxygen and carbon on surface. Porous implants presented a lower titanium concentration at the surface when compared to the machined ones. Quantitative analysis shows about 7\% of nitrogen on the surface of the Conexão implant and traces of silicon were observed on Neodent and SIN implants, and small amount of phosphorous was found on the Nobel implant surface.

XPS wide scans of Neodent, SIN, Conexão, and Nobel Biocare machined and porous implants before and after immersion on SBF for 21 days are presented in Fig. 1 to 4.

SEM images obtained before immersion on SBF showed slight differences among machined implants. In lower magnification, it was possible to identify rounded, well defined contour of threads of the four manufacturers on both types, machined and porous implants. High magnification micrograph
TABLE I. Surface elemental composition of machined (M) and porous (P) surface implants before (B) immersion in SBF.

\begin{tabular}{c|c|c|c|c|c|c|c|c|c} 
& \multicolumn{7}{|c|}{ Surface concentration (atomic \%) } \\
Sample & $\mathrm{O}$ & $\pi$ & $\mathrm{C}$ & $\mathrm{Na}$ & $\mathrm{N}$ & $\mathrm{Ca}$ & $\mathrm{Cl}$ & $\mathrm{P}$ & $\mathrm{Si}$ \\
\hline B1M & 52 & 14 & 33 & - & 1 & - & - & - & - \\
\hline B2M & 47 & 12 & 38 & - & 2 & - & - & - & - \\
\hline B3M & 48 & 15 & 32 & - & 3 & - & - & - & 2 \\
\hline B4M & 50 & 20 & 30 & - & - & - & - & - & - \\
\hline B1P & 42 & 6 & 49 & - & - & - & - & - & 3 \\
\hline B2P & 35 & 7 & 53 & - & - & - & - & - & 5 \\
\hline B3P & 50 & 10 & 32 & - & 7 & - & - & - & - \\
\hline B4P & 50 & 12 & 35 & - & - & - & - & 2 & -
\end{tabular}

TABLE II. Surface elemental composition of implants after (A) 21 days of immersion in $\operatorname{SBF}(*=$ traces $)$.

\begin{tabular}{c|c|c|c|c|c|c|c|c|c} 
& \multicolumn{1}{|c}{ Surface concentration (atomic\%) } \\
Sample & $\mathrm{O}$ & $\mathrm{Ti}$ & $\mathrm{C}$ & $\mathrm{Na}$ & $\mathrm{N}$ & $\mathrm{Ca}$ & $\mathrm{C}$ & $\mathrm{P}$ & $\mathrm{S}$ \\
\hline A1M & 44 & 5 & 37 & 2 & 6 & 2 & 3 & $*$ & - \\
\hline A2M & 37 & 2 & 50 & 1 & 7 & $*$ & 2 & $\star$ & - \\
\hline A3M & 34 & 3 & 50 & 2 & 6 & 2 & 2 & 2 & - \\
\hline A4M & 39 & 4 & 46 & 1 & 5 & 2 & 3 & $*$ & - \\
\hline A1P & 35 & 2 & 48 & 3 & 4 & 1 & 4 & 2 & - \\
\hline A2P & 32 & 1 & 56 & 2 & 3 & 1 & 4 & $*$ & - \\
\hline A3P & 50 & 4 & 34 & 2 & 3 & 3 & 1 & 3 & - \\
\hline A4P & 50 & 6 & 31 & 2 & 3 & 3 & 2 & 3 & -
\end{tabular}

$(3500 \times)$ of machined implants for all 4 manufacturers showed unidirectional striations likely due to the machining process. Neodent, SIN and Conexão presented differences on porosity aspects probably related to particular surface treatment dispensed by each manufacturer. Nobel porous implant has a peculiar porosity aspect with regular distribution of porous along the surface, markedly different from other brands. High magnification SEM micrograph are presented in Fig. 5 and Fig. 6. They were labeled according to the manufacturer.

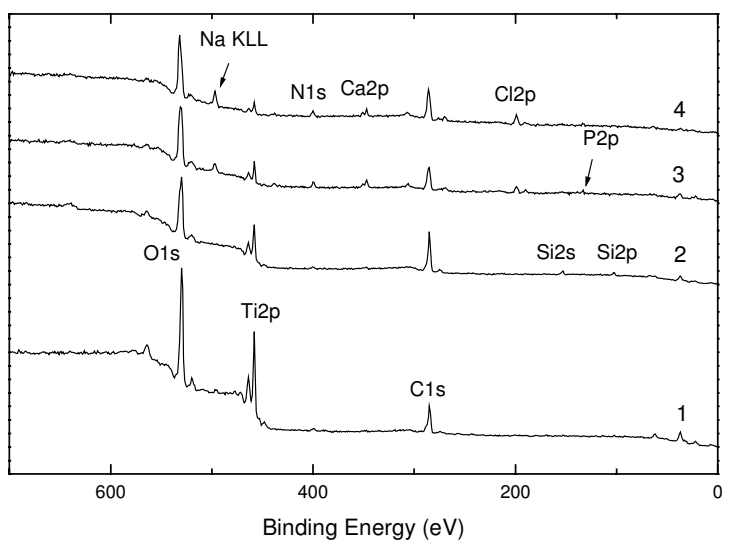

FIG. 1: XPS wide scans of Neodent implants before and after SBF immersion for 21 days: (1) machined surface implant; (2) porous surface implant; (3) machined surface implant, after SBF immersion; and (4) porous surface implant after SBF immersion. 


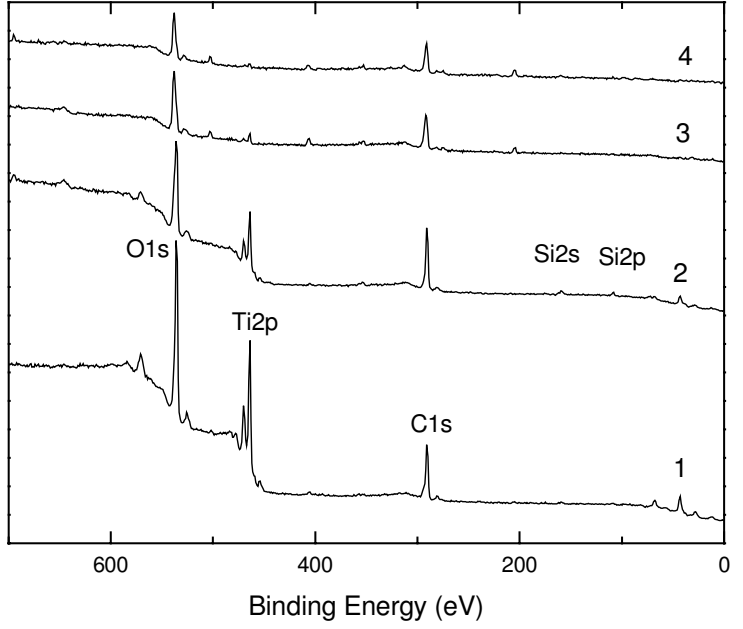

FIG. 2: XPS wide scans of SIN implants before and after SBF immersion for 21 days: (1) machined surface implant; (2) porous surface implant; (3) machined surface implant, after SBF immersion; and (4) porous surface implant after SBF immersion.

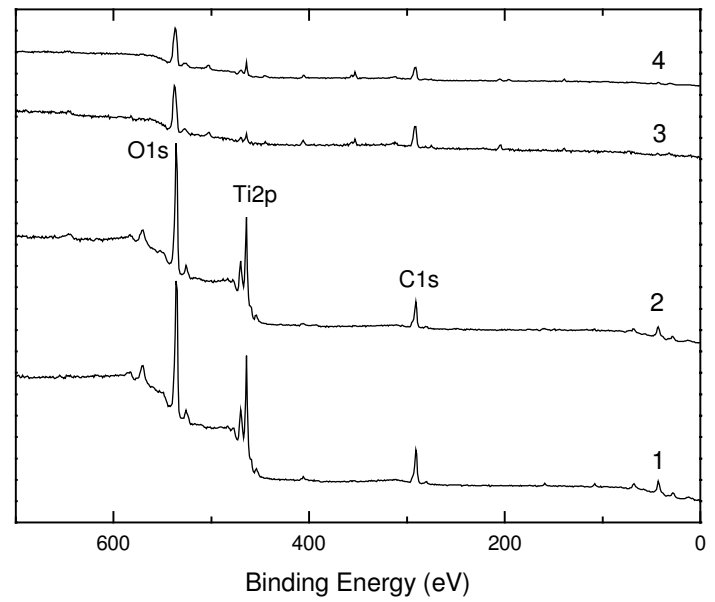

FIG. 3: XPS wide scans of Conexão implants before and after SBF immersion for 21 days: (1) machined surface implant; (2) porous surface implant; (3) machined surface implant, after SBF immersion; and (4) porous surface implant after SBF immersion.

\section{DISCUSSION}

The XPS analysis showed that dental implants surface consisted of oxidized titanium (mainly $\mathrm{TiO}_{2}$ ), carbon, oxygen and a few amount of contaminants like N, P and Si. Implant surface constituents and contaminants are frequently related to bulk composition and to surface modification treatments. Some authors [3, 11, 17 - 19], have reported that surface findings vary according to each manufacturer procedure technique and the presence and even variation of elements concentration should not be related to future success or failure of an

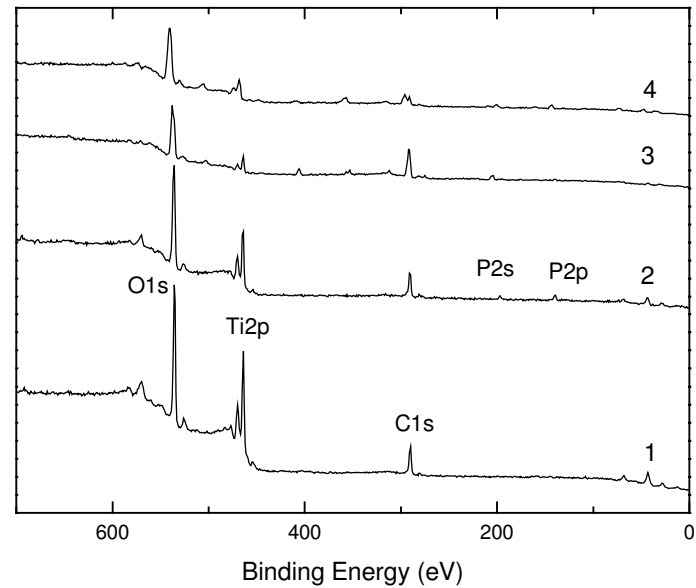

FIG. 4: XPS wide scans of Nobel Biocare implants before and after SBF immersion for 21 days: (1) machined surface implant; (2) porous surface implant; (3) machined surface implant, after SBF immersion; and (4) porous surface implant after SBF immersion.

implant type or brand. The carbon signal that appears regularly is also related to cleaning agents used on manufacturing stages [8]. Dioxide titanium percentage among Brazilian machined implants, according to XPS quantification, is quite similar and not much lower than in Nobel machined implants. These percentages may be attributed to the similar quality level on machining process of Brazilian manufacturers, who have been through significant development last years. Brazilian porous implants presented higher carbon signal than Nobel ones, probably due to specific manufacturing technique used by Nobel Biocare. Since treatment procedures are kept as industrial secret, it is difficult to know exactly why Nobel implants showed lower carbon signal.

Although some minor differences were found, XPS analysis of Brazilian implants, either machined or porous finishing, showed no discrepancy among surface composition when compared to Nobel Biocare implants, taken as reference in this work. The limited ensemble of three specimens per type of implant used in this study does not allow drawing conclusions about one particular batch, meanwhile it is important to remark that there are few studies of implant surfaces like this and, in this manner, our results can be particularly relevant for the Brazilian dental implant industry, branch that is in expansion. Long-term follow-up studies with Nobel Biocare machined and porous implants [20, 21, 22] reports high degree of clinical success. Considering the surface chemical composition and the absence of discrepancy among tested implants, it is reasonable to say that Brazilian implants reached a good production standard when compared to Nobel Biocare ones. In what concerns surface morphology and the importance of surface roughness for implant incorporation, the major difference found on this study was for the porous implants. It is known that each manufacturer makes use of a specific treatment in order to obtain porosity on surface, as confirmed by SEM images that showed different surface morphology for 

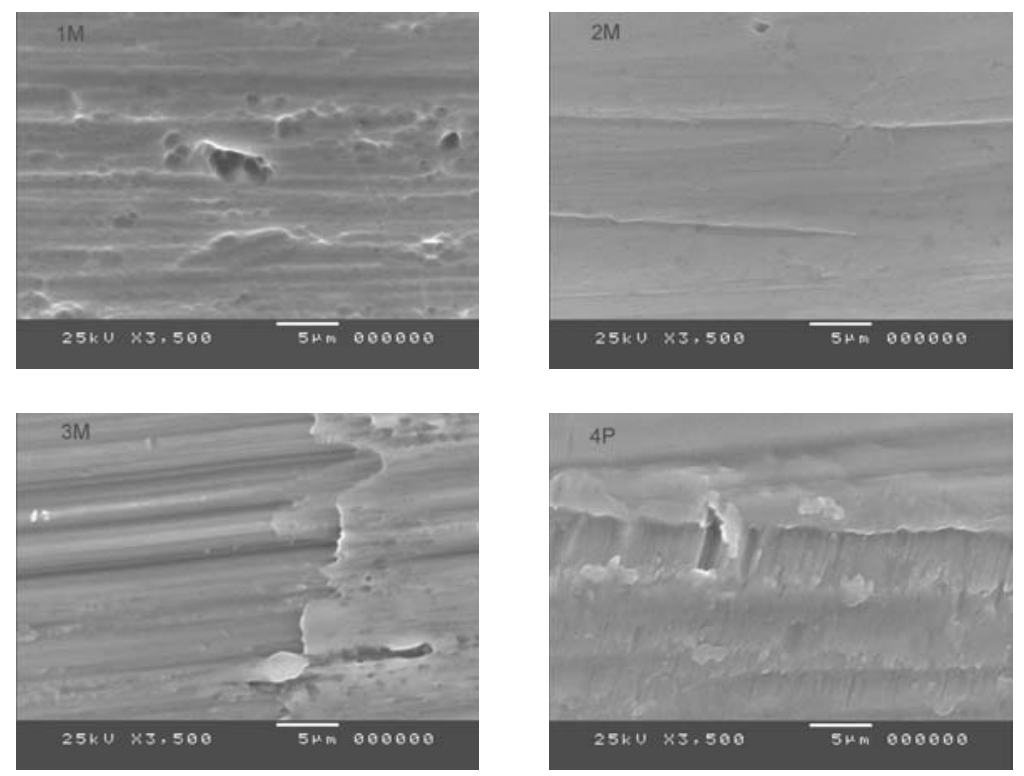

FIG. 5: SEM images (3500X) of titanium machined implant surfaces before immersion on SBF. (1M) Neodent machined implant, (2M) SIN machined implant, (3M) Conexão machined implant, and (4M) Nobel Biocare machined implant.
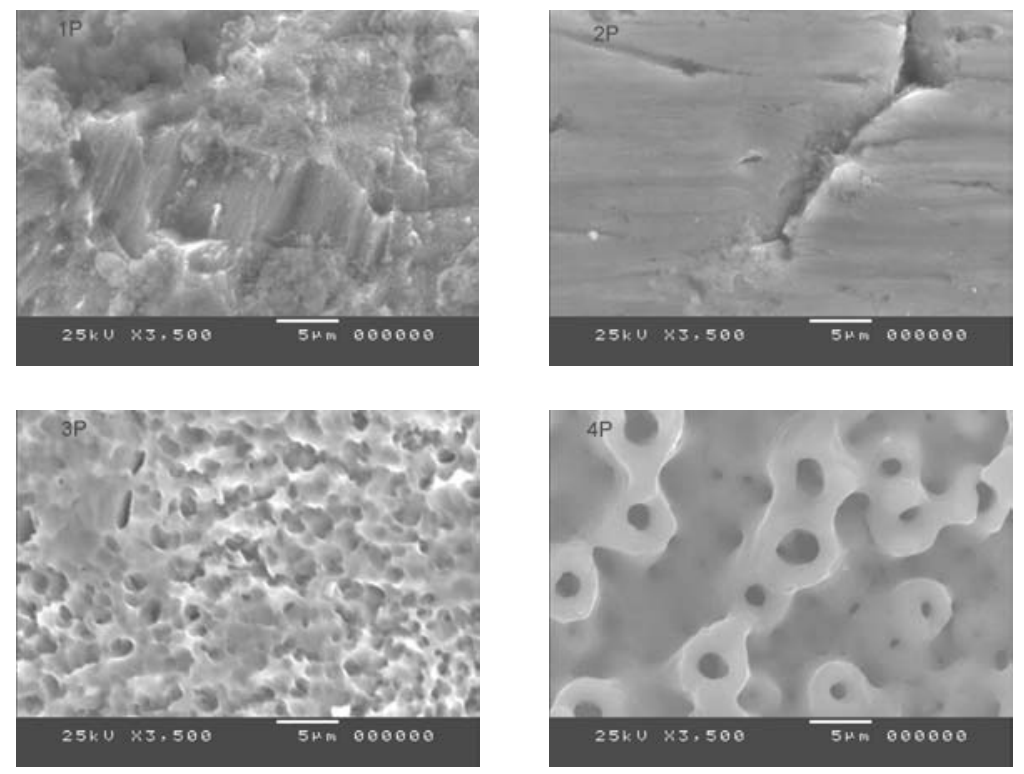

FIG. 6: SEM images (3500X) of titanium porous implant surfaces before immersion on SBF. (1P) Neodent porous implant, (2P) SIN porous implant, (3P) Conexão porous implant, and (4P) Nobel Biocare porous implant.

each porous implant. Nobel's unique pattern of porosity is the most regular among samples. Although the present work have not checked the roughness of tested implants it is important to encourage more studies on this specific topic as far as the surface roughness is reported as a key parameter for the implant retention by works on literature $[23,24]$.

The surface composition analysis of implants after SBF im- mersion test revealed new components like $\mathrm{Ca}, \mathrm{Na}$, and $\mathrm{Cl}$. This in vitro study test the biocompatibility of implants once specific ceramic and metallic biomaterials tend to deposit an apatite layer when immersed on SBF solution, which reproduces the constituents of corporal fluids [25]. The presence of the elements cited above may suggest an apatite layer formation on tested biomaterials when calcium/phosphorus atomic 
concentration ratio is near 1.6. However, the $\mathrm{Ca}: \mathrm{P}$ ratio of tested specimens could not be accurately determined since the concentration of $\mathrm{Ca}$ and $\mathrm{P}$ are at sensitive level of XPS technique.

\section{CONCLUSION}

All the implant surfaces investigated showed titanium dioxide, carbon and oxygen in their chemical composition according to XPS analysis. A few amounts of contaminants like N, $\mathrm{P}$ and Si were also found. After SBF immersion, the implant surfaces showed new components like $\mathrm{Ca}, \mathrm{Na}$ and $\mathrm{Cl}$, but in traces concentration, so the apatite layer formation could not be verified.
The studied Brazilian implants suggested good production standard of manufacturers and showed no discrepancy in chemical composition when compared to Nobel Biocare samples.

Finally, we afirm the relevance of this kind work for dental implantology since there are few studies of implant surface properties and the number of dental implants produced and placed in Brazil is increasing every year.

\section{Acknowledgement}

CDTN/CNEN, CNPq and Fapemig for the financial support and NEODENT, SIN, CONEXÃO, for the donation of titanium dental implants.
[1] P. I. Branemark, U. Breine, R. Adell et al., Scand. J. Plast. Reconstr. Surg. 3, 81 (1969).

[2] R. Adell, U. Lekholm, B. Rocler, and P. I. Branemark, Int. J. Oral Surg. 10, 387 (1981).

[3] C. Massaro, P. Rotolo, F. de Riccardis, E. Milella et al., J. Mater. Sci: Mater. Med. 13, 535 (2002).

[4] T. Albrektsson, P.I. Branemark, B. O. Hanson, and J. Lindström, Acta Orhtop. Scand. 52, 155 (1981).

[5] K. A. Thomas, S. Cook, J. Biomed. Mater. Res. 19, 875 (1985).

[6] A. Schroeder, E. Van der Zypen, Stich et al., J. Maxilofacial Surg. 9, 15 (1981).

[7] J. Lausmaa, J. Electron Spectrosc. Relat. Phenom. 81, 343 (1996).

[8] B. Kasemo and J. Lausmaa, J. Biomed. Mater. Res. 22, 145 (1988).

[9] J. Woodman, J. Jacobs, J. Galante, and R. Urban, J. Orthop. Res. 1, 421 (1984).

[10] S. Smukler-Monkler, T. Testori, and J. P. Bernard, J. Biomed. Mater. Res. 69, 46 (2004).

[11] C. Sitting, M. Textor, N. D. Spencer, and M. Wieland, J. Mater. Sci: Mater. Med. 10, 35 (1998).

[12] J. P. Lucchini, J. L. Aurelle, M. Therin, K Donath, and W. Beker, Clin. Oral Impl. Res. 7, 397 (1996).

[13] C. N. Elias, J. H. C. Lima, M. P. da Silva, and C. A. Muller, Surface Engeneering 18, 46 (2002).

[14] J. A. Ekelund, L. W. Lindquist, G. E. Carlson, and T. Jemt, Int.
J. Prothodont. 16, 602 (2003).

[15] R. Glauser, P. Ruhstaller, S. Windish, A. Zembic, A. Lundgren, J. Gottlow, and C. H. Hammerle, Clin. Implant Dent. Relat. Res. 7, 52 (2005).

[16] J. F. Molder, W. F. Stickle, P. E. Sobol, K. D. Bomen, and J. Chastain, Handbook of X-ray Photoelectron Spectroscopy, Perkin-Elmer Corporation, Physical Electronics Division, Minnesota (1992).

[17] L. A. Sena, N. C. C. Rocha, M. C. Andrade, and G. A. Soares, Surf. Coat. Technol. 166, 254 (2003).

[18] H. E. Placko, S. Mishra, J. J. Weimer, and L. C. Lucas, Int. J. Oral Maxillofac. Implants 15, 355 (2000).

[19] M. P. Casaletto, G. M. Ingo, S. Kaciulis, G. Mattogno, L. Pandolfi, and G. Scavia, Appl. Surf. Sci. 172, 167 (2001).

[20] J. A. Ekelund, L. W. Lindquist, G. E. Carlsson, and T. Jemt, Int. J. Prosthodont. 16 (6) 602 (2003).

[21] R. Adell, B. Eriksson, U. Lekholm, P. I. Branemark, and T. Jemt, Int. J. Oral. Maxillofac. Implants 5 (4), 347 (1990).

[22] A. M. Roos-Jansaker, C. Lindahl, H. Renvert, and S. Renvert, J. Clin. Periodontol. 33 (4), 283 (2006).

[23] A. Wennerberg, Int. J. Mach. Tools Manufact. 38 (5-6), 657 (1998).

[24] H. Hahn, W. Palich, J. Biomed. Mater. Res. 4, 571 (1970).

[25] T. Kokubo, H. Kushitani, S. Sakka, T. Kitsugi, and T. Yamamuro, J. Biomed. Mater. Res. 24, 721 (1990). 